\title{
DnaJ Proteins Regulate WUS Expression in Shoot Apical Meristem of Arabidopsis
}

\author{
Tianqi Jia, Fan Li, Shuang Liu, Jin Dou and Tao Huang *
}

check for updates

Citation: Jia, T.; Li, F.; Liu, S.; Dou, J.; Huang, T. DnaJ Proteins Regulate WUS Expression in Shoot Apical Meristem of Arabidopsis. Plants 2021, 10, 136. https://doi.org/10.3390/ plants10010136

Received: 17 November 2020 Accepted: 31 December 2020 Published: 12 January 2021

Publisher's Note: MDPI stays neutral with regard to jurisdictional clai$\mathrm{ms}$ in published maps and institutional affiliations.

Copyright: (C) 2021 by the authors. Licensee MDPI, Basel, Switzerland. This article is an open access article distributed under the terms and conditions of the Creative Commons Attribution (CC BY) license (https:// creativecommons.org/licenses/by/ $4.0 /)$.

\author{
School of Life Sciences, Xiamen University, Xiamen 361102, China; 21620150150523@stu.xmu.edu.cn (T.J.); \\ 21620181153678@stu.xmu.edu.cn (F.L.); 21620201153217@stu.xmu.edu.cn (S.L.); doudoukuaile@yeah.net (J.D.) \\ * Correspondence: Huangtao@xmu.edu.cn
}

\begin{abstract}
WUSCHEL (WUS) protein regulates stem cell function in shoot apical meristem of Arabidopsis. The expression of WUS gene is strictly regulated by developmental cues and environmental factors. As DnaJ domain-containing proteins, SDJ1 and SDJ3 have been proven to play an important role in transcriptional activation of promoter methylated genes. Here, we showed that three DnaJ domain-containing proteins including SDJ1 and SDJ3 can bind WUS protein as a complex, which further maintain the expression of WUS gene by binding to WUS promoter. We propose a model how DnaJ domain-containing proteins are involved in the self-regulation of WUS gene in stem cells maintenance of Arabidopsis.
\end{abstract}

Keywords: stem cell; WUS; DnaJ proteins

\section{Introduction}

The continual propagation and differentiation of stem cells provide a basis for the postembryonic growth and development of plants. The stem cells in shoot apical meristem (SAM) of Arabidopsis are defined by the homeodomain proteins WUSCHEL (WUS), which is expressed in the organization center (OC). WUS protein can move to stem cell region where it can activate downstream gene CLVATA3, which conversely inhibit WUS expression, thereby maintaining stem cell homeostasis in SAM [1-3].

Previous studies have demonstrated that abiotic stresses can induce the accumulation of heat shock proteins (HSPs) at different molecular weights [4,5]. As a subfamily of heat shock protein, HSP40s are characteristic of the conserved DnaJ-domain that is responsible for interaction with HSP70s [6-8]. HSP40s can be divided into seven subfamilies according to the containing J-domains in Arabidopsis. DnaJA, DnaJB, and DnaJC subfamilies contain a typical J-domain that interacts with HSP70 proteins [9]. DnaJD, DnaJE, DnaJF, and DnaJG proteins are HSP70-independ because of the lacking of a typical J-domain [8,10,11]. HSP40/DnaJ-proteins are involved in the protein homeostasis by regulating protein folding/refolding, assembly, translocation, and stabilization under abiotic stress [10,12,13]. Previous researches have demonstrated the crucial roles of DnaJ-proteins in growth and development, hormone regulation, and acclimation of plants to abiotic stress [14-19]. As two members of DnaJD subfamily, SDJ1 and SDJ3 have been shown to interact with SUVH1 or SUVH3 protein as a SUVH-SDJ complex, which further mediates the transcriptional activation of promoter methylated genes $[20,21]$. SDJ1 protein also has been shown to be involved in flowering time control of Arabidopsis [18]. In this work, we showed that SDJ1 and SDJ3 proteins also interact with WUS protein as a complex which further regulate WUS expression by binding to WUS promoter.

\section{Results and Discussion}

\subsection{WUS Interacts with DnaJ Proteins In Vivo and In Vitro}

When we used WUS protein as a bait to screen binding proteins from an Arabidopsis library by yeast-two-hybrid, one DnaJ-domain protein encoded by At1g62970 was identified 
as a possible WUS-binding protein, which was already named as SDJ3. There are another two DnaJ-domain containing proteins encoded by At5g64360 and At5g09540 sharing high homologue with SDJ3 in Arabidopsis genome. The protein encoded by At5g64360 was already named as SDJ1. SDJ1 and SDJ3 also interacted with WUS protein in yeast (Figure 1a). The interactions between SDJ1/SDJ3/At5g09540 and WUS were also confirmed by bimolecular fluorescence complementation (BiFC) assays in epidermal cells of tobacco (Nicotiana benthamiana). Strong YFP fluorescence was observed in nuclei when WUS-YFPn was cotransformed with SDJ1-YFPc, SDJ3-YFPc and At5g09540-YFPc, respectively (Figure 1b). The interactions between SDJ1/At5g09540and WUS were further confirmed by in vitro pull-down assay. The glutathione S-transferase (GST)-WUS, but not GST, bound the maltose-binding protein (MBP)-fused SDJ1, and MBP-At5g09540 proteins, respectively (Figure 1c). Therefore, DnaJ proteins can bind WUS protein as a complex independent of HSP70 proteins. Interactions in planta between SDJ1/SDJ3/At5g09540 proteins and WUS were also examined using co-immunoprecipitation assays. When HA-tagged SDJ1/SDJ3/At5g09540 proteins and GFP:WUS protein were transiently expressed in the epidermal cells of tobacco leaves, GFP:WUS protein bound SDJ1, SDJ3 and At5g09540, respectively (Figure 2d-f). Taken together, the interactions between SDJ1/SDJ3/At5g09540 proteins and WUS protein were confirmed with multiple methods.

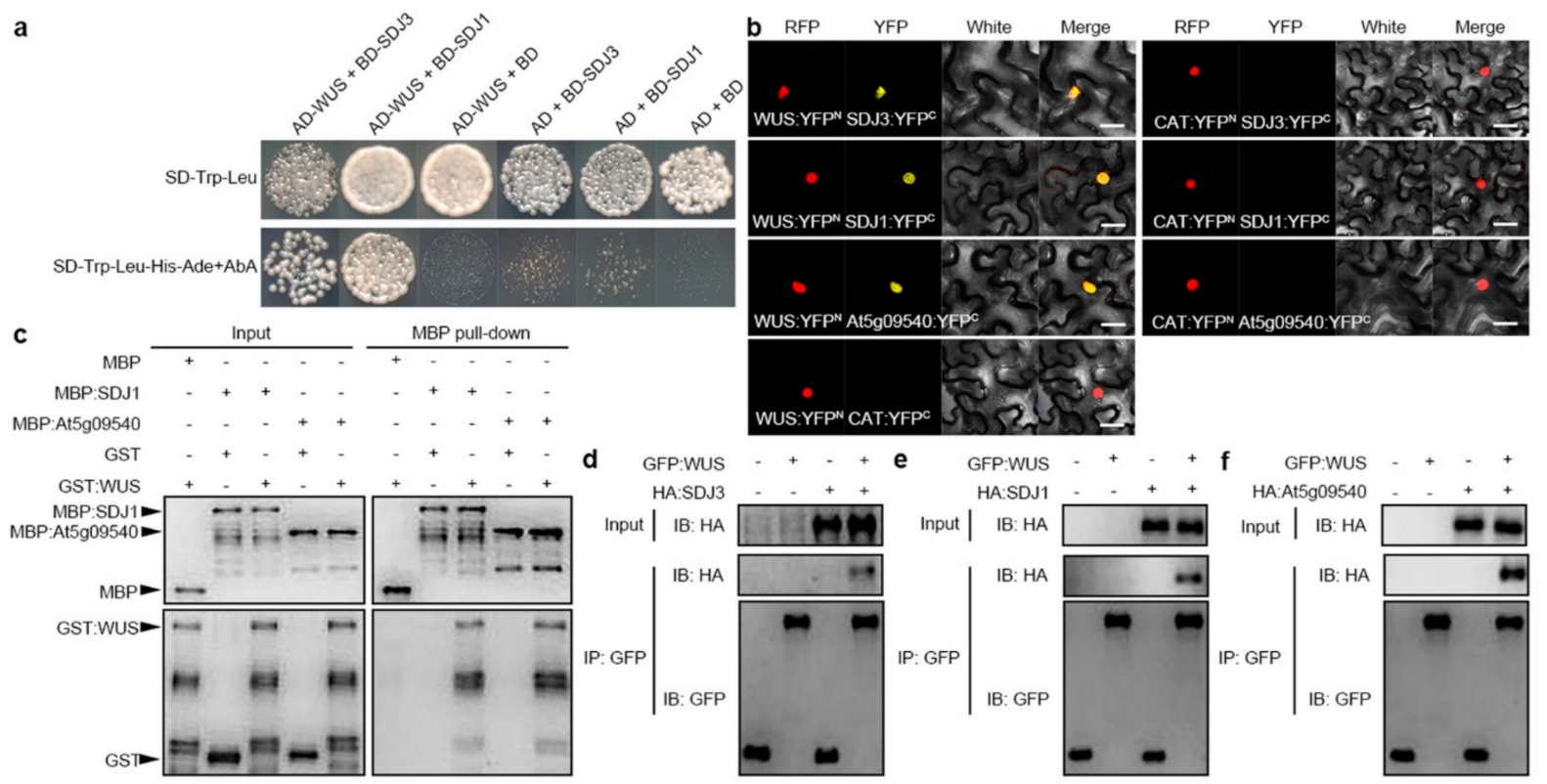

Figure 1. WUS protein interacts with DnaJ proteins (a) WUS protein interacts with SDJ1 and SDJ3 proteins in Yeasttwo-hybrid assays. (b) Bimolecular fluorescence complementation in tobacco epidermal cells. WUS:YFPn protein in combination with SDJ3:YFPc, SDJ1:YFPc, and At5g09540:YFPc, respectively, was colocalized with Coilin:RFP protein in nucleus. CAT:YFPn and CAT:YFPc were used in control assays. Scale bar $=25 \mu \mathrm{m}$. (c) Input of recombinant proteins detected by immunoblotting with anti-GST antibody and anti-MBP antibody (Left) and pull down of GST-tagged WUS protein through MBP-tagged SDJ1 and MBP-tagged At5g09540 proteins detected by immunoblotting with anti-GST antibody (right). (d-f) Co-immunoprecipitation of GFP:WUS and HA:SDJ3 (d), GFP:WUS and HA:SDJ1 (e), GFP:WUS and HA:At5g09540 (f) detected by immunoblotting with anti-HA antibody. 


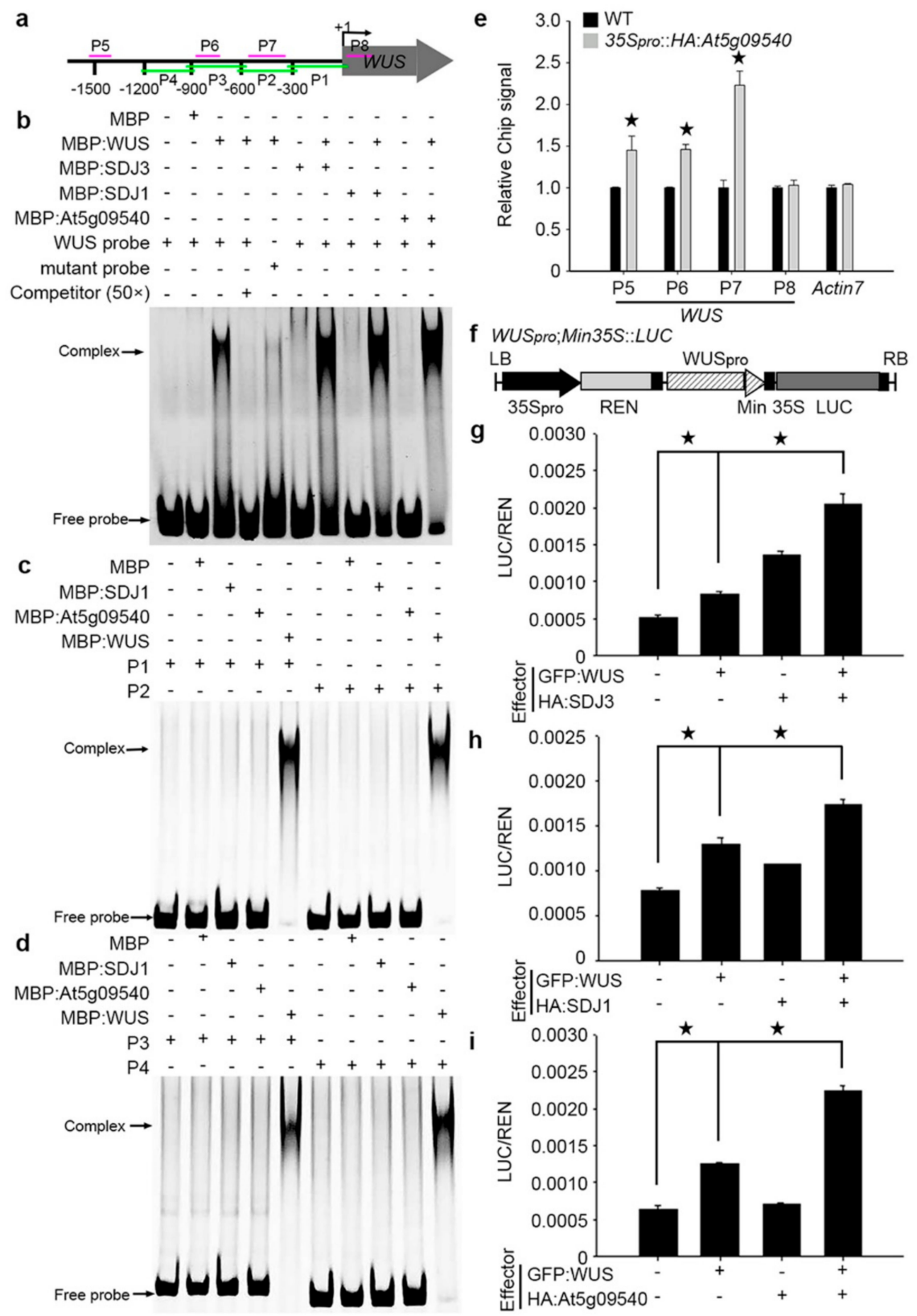

Figure 2. WUS-DnaJ complexes bind to WUS promoter and regulate WUS promoter activity. (a) Diagram of amplicon locations in WUS promoter. (b) DnaJ proteins bind to Texas red-labeled WUS promoter probe via the interaction with WUS protein as a complex in EMSA assay. The unlabeled probe was used as competitor. The TAAT box was substituted by CCCC in WUS mutant probe to abolish the binding of WUS protein. (c,d) SDJ1 and At5g09540 proteins failed to bind to P1(-312 bp-+25 bp) and P2 (-608 bp--285 bp)regions (c) and P3 (-926 bp--580 bp)and P4(-1203 bp--895 bp) regions (d) of WUS promoter in EMSA assay. (e) Chromatin immunoprecipitation of At5g09540 protein with different regions (P5, P6, P7, P8) of WUS promoter and an Actin7 promoter region in $35 S_{\text {pro }}:$ HA:At5g09540 plants. P5(-1570 bp--1481bp), $\mathrm{P} 6(-869 \mathrm{bp}--774 \mathrm{bp})$, and P7( $-515 \mathrm{bp}--340 \mathrm{bp})$ regions contain TAAT box, but not P8 (+12 bp-+121 bp) region. The ChIP signal was calculated with three independent biological replicates, Student-t test, ${ }^{*} p<0.05$. (f-i) LUC/REN activity in tobacco cells co-transformed with WUSpro;min35S::LUC reporter construct and indicated effectors. (f) Diagram ofWUSpro; Min35S::LUC reporter construct. 35S: CaMV 35S promoter; WUSpro: 2.2 Kb WUS promoter (-1--2200 bp); Min35S: 47 base pair 35S minimal element; REN: Renilla luciferase, LUC: firefly luciferase. LB/RB: T-DNA left or right border. The WUS promoter activity was significantly increased by WUS protein in combination with SDJ3 (g), SDJ1 (h), and At5g09540 (i), respectively. Error bar $=$ mean $\pm \operatorname{SEM}\left(n=4\right.$ biological replicates). Student-t test, ${ }^{*} p<0.05$. 


\subsection{DnaJ Proteins Function as a Co-Factor of WUS in Activating WUS Expression}

Previous studies demonstrated that WUS protein can bind to TAAT motif in the promoter of downstream target genes [22]. WUS promoter also contains many TAAT motifs, indicating that WUS might bind to its own promoter for self-regulation. We examined whether SDJ1/SDJ3/At5g09540 proteins might bind to WUS promoter via interaction with WUS protein as a complex using electrophoretic mobility shift assay (EMSA). Our results showed that WUS protein can specifically bind to TAAT motif in a WUS promoter probe. The substitution of TAAT motif with CCCC abolished the binding to WUS protein to this promoter probe. WUS protein bound to its promoter more efficiently in the presence of SDJ1, SDJ3, and At5g09540 proteins, respectively (Figure 2a,b). SDJ1 and At5g09540 proteins on their own failed to bind to WUS promoter when different promoter regions were used in EMSA (Figure 2c,d). However, the binding of At5g09540 to different regions (P5-P7) of WUS promoter, but not coding region (P8), in 35S pro::HA:At5g09540 plants was confirmed using Chromatin immunoprecipitation (CHIP) assay (Figure 2e), demonstrating that At5g09540 protein can bind to WUS promoter via the interaction with endogenous WUS protein as a complex.

To confirm the direct effects of WUS-DnaJ complex on the activities of WUS promoter, dual luciferase assays were conducted in tobacco leaf epidermal cells in which

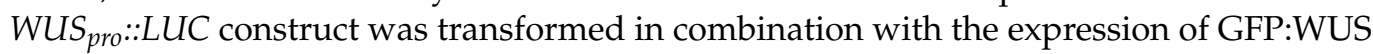
and HA-tagged SDJ1, SDJ3, and At5g09540 proteins, respectively. The luciferase activity was dramatically increased when GFP:WUS and SDJ1/SDJ3/At5g09540 proteins were combined in comparison with GFP, GFP:WUS or SDJ1/SDJ3/At5g09540 proteins alone (Figure $2 \mathrm{f}-\mathrm{i}$ ). These results demonstrated a positive role of WUS-SDJ1/SDJ3/At5g09540 complex in WUS promoter activity.

\subsection{Disruption of DnaJ Proteins by Chimeric Repressor Silencing Technology Led to Premature Termination of SAM}

A transcriptional activator can be converted into a strong repressor by fusion with the ERF-associated amphiphilic repression (EAR) motif repression domain (SRDX), which then specifically suppress the expression of target genes by binding to their promoters [23-25]. This designated chimeric repressor gene silencing technology (CRES-T) can also be used to examine the protein-protein interactions and protein functions in growth and development of plants [26]. The $35 S_{\text {pro }}:: S D J 1-S R D X, 35 S_{p r o}:: S D J 3-S R D X$ and $35 S_{p r o}:: A t 5 g 09540-S R D X$ transgenic plants were also created to examine the role of SDJ1/SDJ3/At5g09540 proteins in WUS expression and stem cell maintenance in planta. The strong $35 S_{\text {pro }}:: S D J 3-S R D X$ lines produced an umbrella structures on the top end of shoot, which is similar to the typical phenotype of wus mutant. The $35 S_{\text {pro }}:: S D J 1-S R D X$ plants and $35 S_{\text {pro }}:$ At5g09540-SRDX plants also showed the premature termination of SAM (Figure 3a-f). GUS staining showed that the WUS promoter activity is significantly repressed in the SAM of $35 S_{p r o}:: S D J 1-S R D X$ $W_{U S}$ pro::GFP:GUS plants (Figure 3g,h). Taken together, SDJ1/SDJ3/At5g09540 proteins can interact with WUS as a complex which further regulate the expression of WUS gene by binding to WUS promoter. 

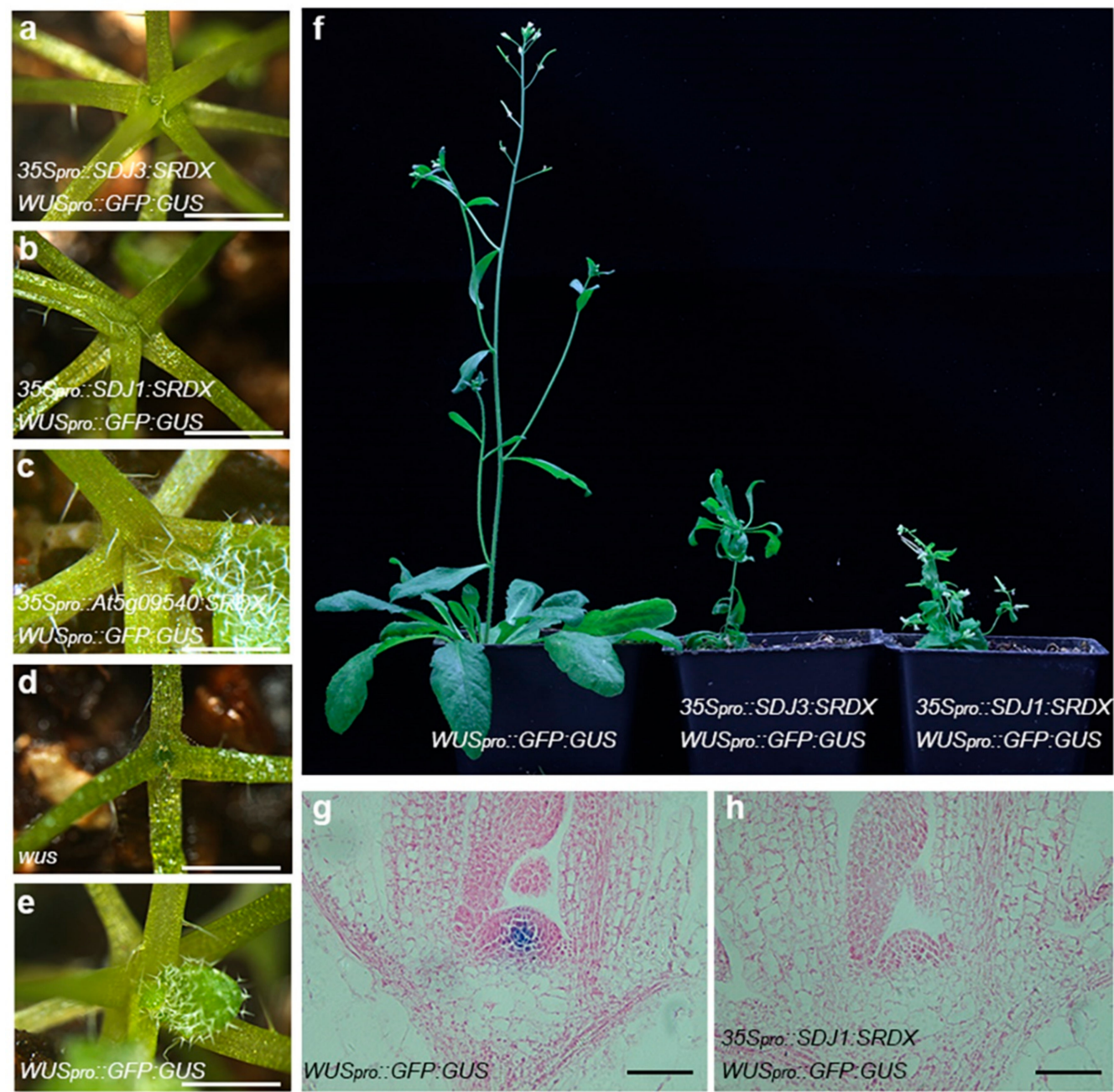

Figure 3. Overexpression of DnaJ-SRDX protein inhibits SAM development in Arabidopsis. (a-e) The premature termination of SAM in strong lines of $35 S_{\text {pro }}:: S D J 3-S R D X$ WUS $S_{\text {pro }}:: G F P: G U S$ plant (a), 35S pro::SDJ1-SRDX WUS pro::GFP:GUS plant (b),

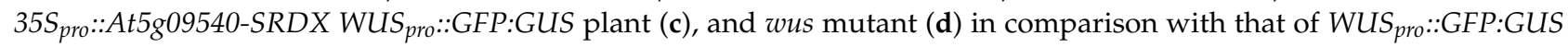

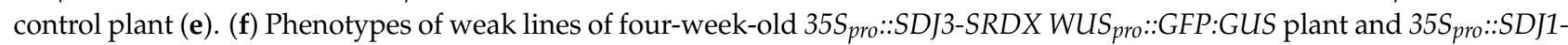
$S R D X$ WUS $S_{\text {pro }}:$ GFP:GUS plant in comparison with WUS pro::GFP:GUS control plant. (g,h) WUS promoter activity in $35 S_{\text {pro }}:: S D J 1-S R D X$ WUS $_{\text {pro }}:$ GFP:GUS plant (h) in comparison with WUS $S_{\text {pro }}:$ GFP:GUS plant (g) examined by GUS staining. Scale bar $=5 \mathrm{~mm}$ in $(\mathbf{a}-\mathbf{e}), 50 \mu \mathrm{m}$ in $(\mathbf{g}, \mathbf{h})$.

\subsection{SDJ1 and SDJ3 Genes are Expressed in the SAM, RAM and Vascular Tissues of Leaf and Hypocotyl}

To examine the expression pattern of SDJ1 and SDJ3 genes, gSDJ3::GFP:GUS and gSDJ1::GFP:GUS transgenic plants were created to express SDJ3:GFP:GUS and SDJ1:GFP:GUS fusion proteins, respectively, under the control of their own promoters (Figures $4 \mathrm{a}$ and $5 \mathrm{a}$ ). The expression of SDJ3:GFP:GUS protein was only detected at mature stage during embryogenesis (Figure 4b-e). However, SDJ1:GFP:GUS protein was already expressed from globular stage during embryogenesis (Figure $5 \mathrm{~b}-\mathrm{e}$ ). After germination, GUS staining showed that SDJ3:GFP:GUS protein and SDJ1:GFP:GUS protein are mainly expressed in SAM, RAM and vascular tissues of leaf and hypocotyl, as well as younger but not fully differentiated leaves (Figures $4 \mathrm{f}-\mathrm{O}$ and $5 \mathrm{f}-\mathrm{o}$ ). In addition, SDJ1/SDJ3/At5g09540 in fusion with GFP protein was transiently expressed and located in nucleus of tobacco epidermal cells (Figure 6). 


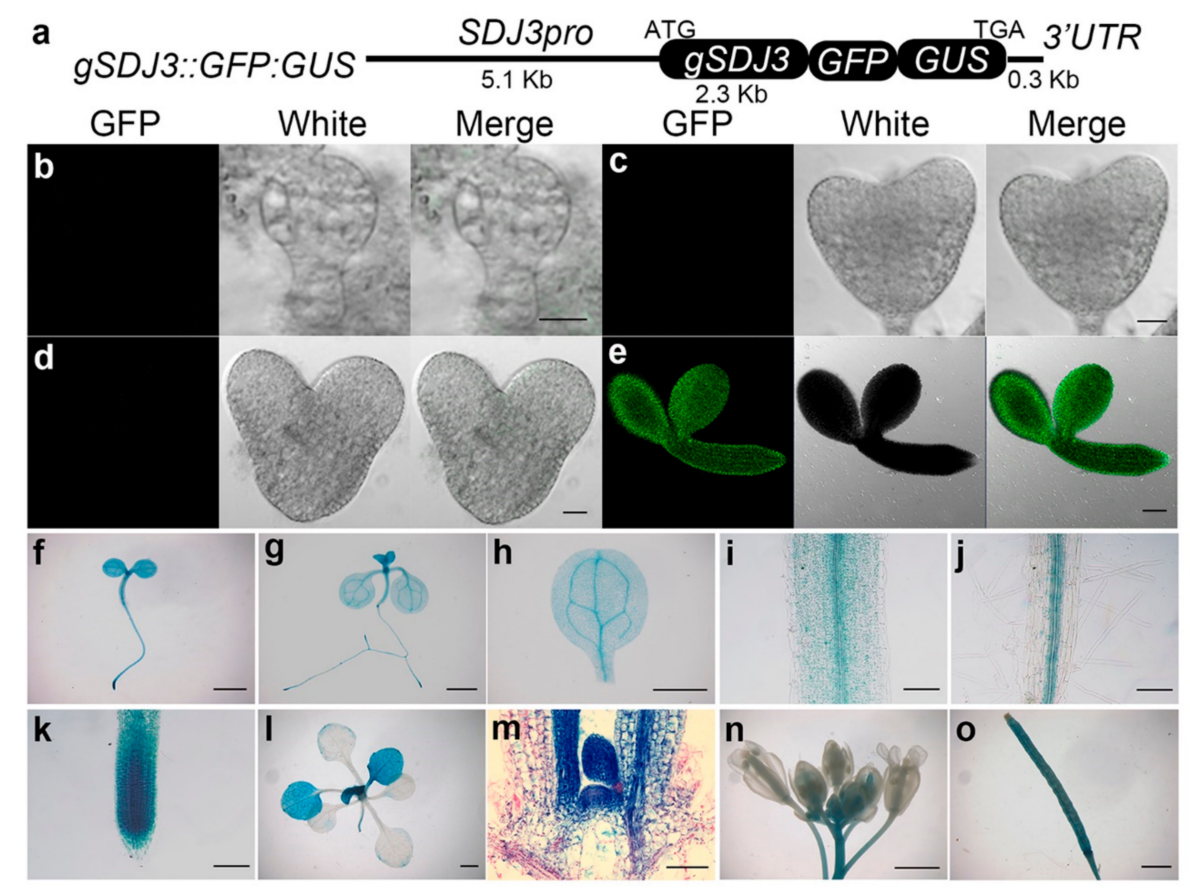

Figure 4. Expression of $S D J 3$ gene in different organs at different developmental stages. (a) Diagram of $g S D J 3:: G F P: G U S$ construct. (b-e) SDJ3:GFP:GUS fusion protein is expressed at mature stage (e), but not global stage (b), heart stage (c), and torpedo stage (d) during the embryogenesis of $g S D J 3:: G F P: G U S$ plant by GFP fluorescence scanning. (f-o) Expression of SDJ3:GF:GUS fusion protein in 3-day-old seedling (f), 7-day-old seedling (g), cotyledon (h), hypocotyl (i), root (j), and RAM (k) of 7-day-old seedling, 14-day-old seedling (1), SAM of 14-day-old seedling (m), Flower (n), and Silique (o) examined by GUS staining. Scale bar $=10 \mu \mathrm{m}$ in $(\mathbf{b}-\mathbf{d}) ; 50 \mu \mathrm{m}$ in $(\mathbf{e}, \mathbf{m}) ; 1000 \mu \mathrm{m}$ in $(\mathbf{f}-\mathbf{l}, \mathbf{n})$ and $\mathrm{o} ; 100 \mu \mathrm{m}$ in $(\mathbf{i}-\mathbf{k})$.

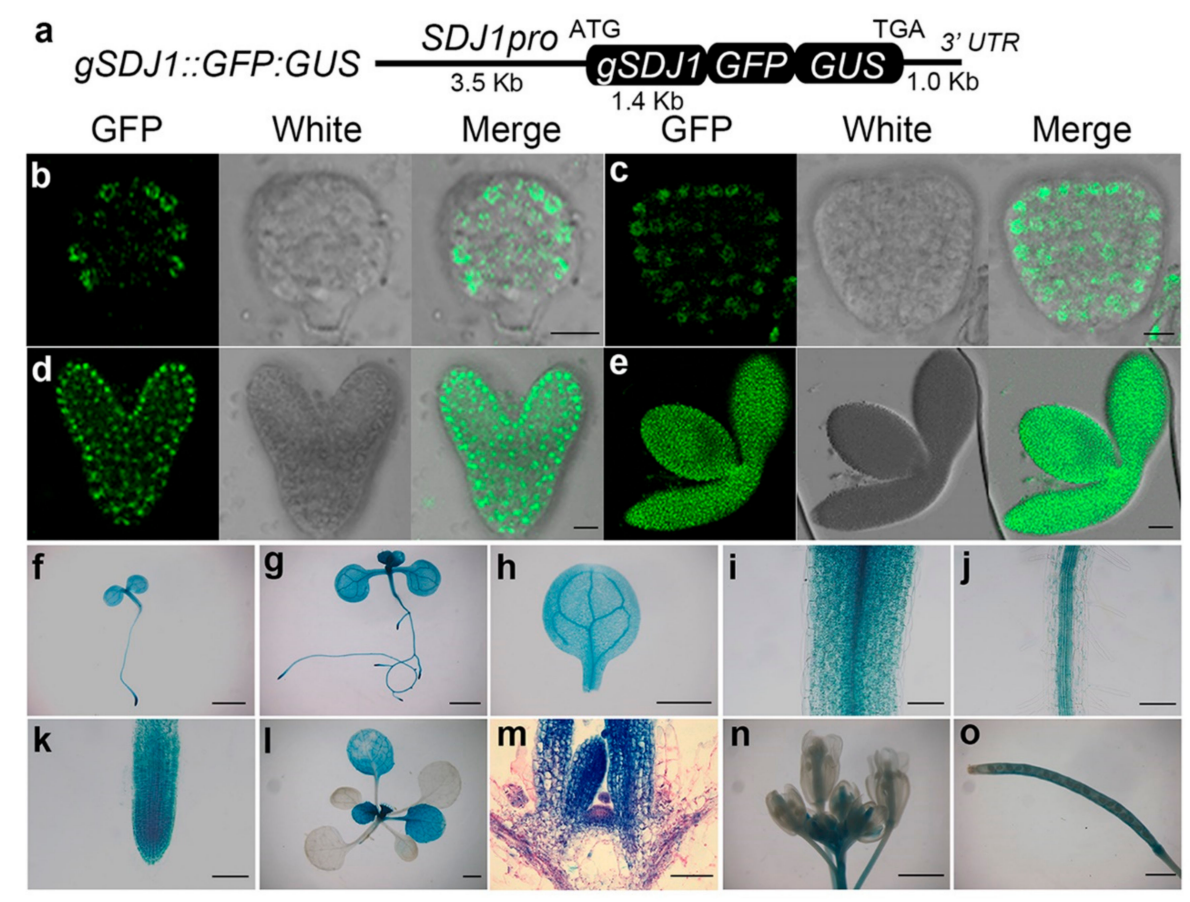

Figure 5. Expression of SDJ1 gene in different organs at different developmental stages. (a) Diagram of gSDJ1::GFP:GUS construct. (b-e) SDJ1:GFP:GUS fusion protein is expressed at global stage (b), heart stage (c), and torpedo stage (d), and mature stage (e) during the embryogenesis of $g S D J 1:$ GFP:GUS plant by GFP fluorescence scanning. (f-o) Expression of SDJ1:GFP:GUS fusion protein in 3-day-old seedling (f), 7-day-old seedling (g), cotyledon (h), hypocotyl (i), root (j), and RAM (k) of 7-day-old seedling, 14-day-old seedling (1), SAM of 14-day-old seedling (m), Flower (n), and Silique (o) examined by GUS staining. Scale bar $=10 \mu \mathrm{m}$ in $(\mathbf{b}-\mathbf{d}) ; 50 \mu \mathrm{m}$ in $(\mathbf{e}, \mathbf{m}) ; 1000 \mu \mathrm{m}$ in $(\mathbf{f}-\mathbf{l}, \mathbf{n})$ and $\mathbf{o} ; 100 \mu \mathrm{m}$ in $(\mathbf{i}-\mathbf{k})$. 


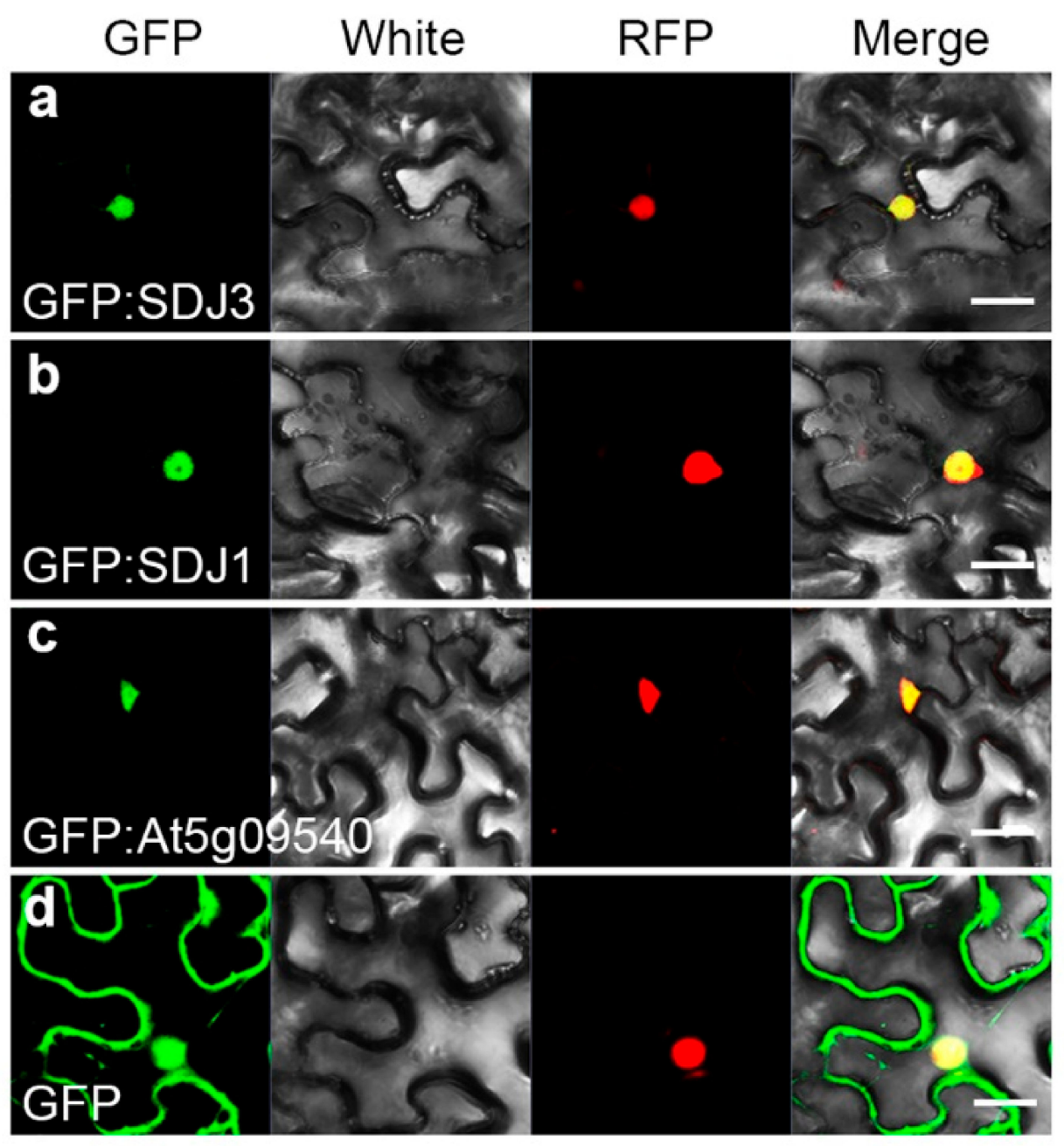

Figure 6. Localization of DnaJ proteins in nucleus. (a-c) The transiently expressed GFP:SDJ3, GFP:SDJ1, and GFP:At5g09540 proteins are colocalized with Coilin:RFP protein in nucleus in tobacco epidermal cells. (d) GFP protein is freely distributed in cytoplasm and nucleus. Scale bar $=25 \mu \mathrm{m}$.

\subsection{DnaJ Proteins Contribute to the Expression of WUS mRNA}

The binding of WUS protein to its own promoter might be necessary for keeping the normal expression level of WUS gene. To explore the roles of SDJ1/SDJ3/At5g09540 genes in growth and development of Arabidopsis, the sdj1, sdj3, and at $5 \mathrm{~g} 09540$ knockout mutants were identified by RT-PCR analysis of the relative endogenous SDJ1/SDJ3/at5g09540 expression (Figure 7a). The sdj1 sdj3 at5g09540 triple mutant was also created by genetic crossing. The sdj1 sdj3 at5g09540 mutant grew normally as WT plants under normal growth condition possibly because other redundant DNAJ domain proteins might also interact with WUS protein as a complex, which also might be involved in WUS expression (Figure 7b). Actually, the DnaJ-domain protein encoded by At4g11930 also interacted with WUS protein in BiFC analysis (Figure S1), indicating that more proteins from DnaJ-domain protein family might interact with WUS protein. WUS mRNA in three-day-old sdj1 sdj3 at5g09540 mutant was decreased to a lower level in comparison with that of WT plants, suggesting that SDJ1/SDJ3/At5g09540 proteins contribute to the expression of WUS mRNA (Figure 7c). In addition, as a downstream target of WUS protein, the expression of CLV3 was not significantly changed in sdj1 sdj3 at5g09540 mutant (Figure 7d). The inflorescence meristem morphology of sdj1 sdj3 at5g09540 mutant was not significantly altered in comparison with WT (Figure 7e,f), indicating that SAM development can tolerate a variation range of WUS expression. Taken together, DnaJ proteins can maintain WUS expression by interacting with WUS protein as a complex which further bind to WUS promoter in SAM of Arabidopsis. 
We also cloned ortholgues of WUS and SDJ1 from Brassica napus. The interaction between BnWUS (CDY30337) and BnSDJ1 (XP_013722826) was also confirmed in BIFC analysis (Figure S2). Therefore, DnaJ proteins might be universally employed as WUS-binding protein to regulate stem cell function in SAM in plant kingdom.
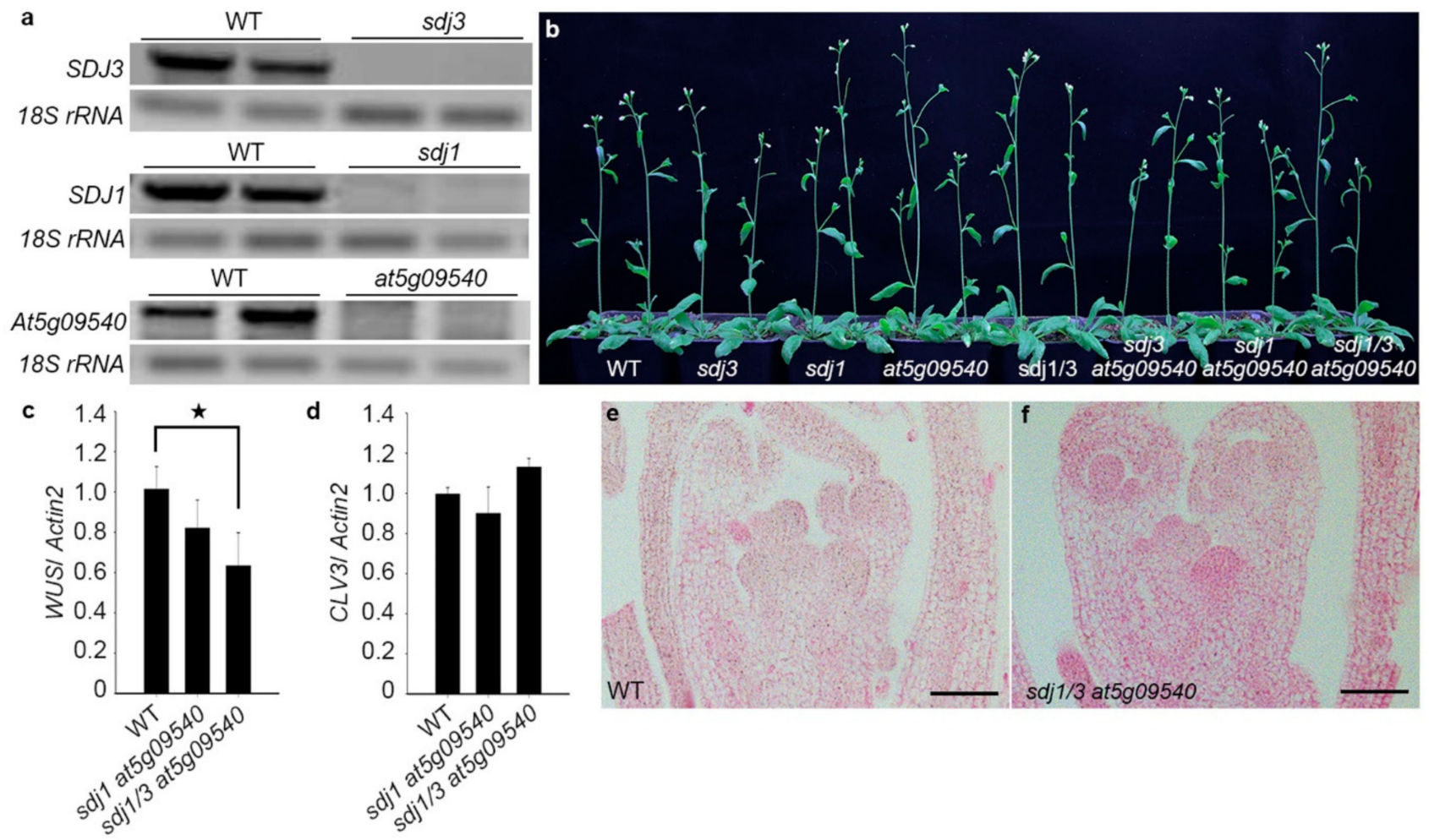

Figure 7. DnaJ protein regulate WUS mRNA expression. (a) RT-PCR analysis of of relative genes in sdj3, sdj1and at $5 g 09540$ mutants. (b) Growth phenotype of WT, sdj3, sdj1, at5g09540, sdj3 sdj1, sdj1 at5g09540, sdj3 at5g09540, and sdj3 sdj1 at5g09540 plants. (c,d) WUS mRNA level and CLV3 mRNA level in WT and sdj3 sdj1 at5g09540 plants by quantitative RT-PCR analysis. Student-t test, ${ }^{*} p<0.05$ (e,f) SAM histology of WT and sdj3 sdj1 at5g09540 plants.

\section{Materials and Methods}

\subsection{Plant Materials and Transformation}

All constructs were introduced into Col-0 by Agrobacterium tumefaciens PMP90 strain according to the reported floral-dip protocol [27]. At least three independent transgenic lines were used for subsequent analyses. The sdj3 mutant (Salk_016979), sdj1 mutant (Salk_021078), at5g09540 mutant (SAIL_735_A07), and wus mutant (Salk_114398) were ordered from the European Arabidopsis Stock Centre. All plants were grown in soil at $22{ }^{\circ} \mathrm{C}$ under long days $(16 \mathrm{~h}$ light $/ 8 \mathrm{~h}$ dark $)$ with white fluorescent light $\left(120 \mu \mathrm{mol} \cdot \mathrm{m}^{-2} \cdot \mathrm{s}^{-1}\right)$.

\subsection{Plasmids Construction for Transgenic Plants}

The CaMV $35 S$ promoter in the $p B 7 G W 2$ vector was replaced with the putative $5.1 \mathrm{~Kb} S D J 3$ promoter $(-1 \mathrm{bp}--5100 \mathrm{bp})$ to create $p B 7 G W 2 \_S D J 3$ pro. The SDJ3 genomic fragment (from translation start codon to stop codon) and $0.3 \mathrm{~Kb}$ downstream region after the coding region were cloned into the $p D O N R 201 \_G F P: G U S$ vector to create $p D O N R 201 \_g S D J 3: G F P: G U S$ for the in-frame fusion of the GFP:GUS with the SDJ3 gene. The gSDJ3:GFP:GUS usion gene was further cloned into $p B 7 G W 2 \_S D J 3$ pro to create the $g S D J 3: G F P: G U S$ construct by LR clonase (Invitrogen, Carlsbad, CA, USA). gSDJ1:GFP:GUS construct containing $3.5 \mathrm{~Kb}$ promoter region, $1.392 \mathrm{~Kb}$ genomic region and $1.0 \mathrm{~Kb}$ downstream region was also created by the same strategy. The SDJ1, SDJ3 and At5g09540 cDNAs were amplified with XbaI (5'-end) and SpeI ( $3^{\prime}$-end) sites and cloned into pDONR201 to create $p D O N R 201-S D J 1 / S D J 3 / A t 5 g 09540$, 
respectively. The GFP cDNA was inserted at the unique XbaI site and unique SpeI site in $p D O N R 201-S D J 1 / S D J 3 / A t 5 g 09540$ to create the $p D O N R 201-G F P: S D J 1 / S D J 3 / A t 5 g 09540$, respectively. The HA tag and SRDX domain (LDLDLELRLGFA) were also cloned into the $p D O N R 201-S D J 1 / S D J 3 / A t 5 g 09540$ to create $p D O N R 201 \_H A: S D J 1 / S D J 3 / A t 5 g 09540$ and pDONR201_SDJ1/SDJ3/At5g09540:SRDX, respectively. These genes harbored in the $p D O N R 201$ was further cloned into $p K 2 G W 7$ to create $35 S_{p r o}:: G F P: S D J 1 / S D J 3 / A t 5 g 09540$, 35S pro::HA:SDJ1/SDJ3/At5g09540 and 35S pro:: SDJ1/SDJ3/At5g09540:SRDX constructs, respectively.

\subsection{Protein Purification}

The WUS cDNA was cloned into pGEX vector and $p M B P-c$ vector, respectively. $S D J 1 / S D J 3 / A t 5 g 09540 \mathrm{cDNAs}$ were also cloned into $p M B P-c$ vector, respectively. The target proteins were expressed in E. coli BL21 with the induction of $0.25-1.0 \mathrm{mM}$ isopropyl $\beta$-D-1thiogalactopyranoside (IPTG) for $9 \mathrm{~h}$ at $16{ }^{\circ} \mathrm{C}$ or $22{ }^{\circ} \mathrm{C}$ and purified using glutathione resin (Thermo Fisher Scientific, Waltham, MA, USA) or amylose resin (New England Bio-Labs, Ipswich, MA, USA).

\subsection{Yeast Two-Hybrid Assay}

WUS CDNA was cloned into $p G A D T 7$ vector. SDJ1 and SDJ3 cDNAs were cloned into $p G B K T 7$ vector. The bait and prey vectors were transformed into Y2HGold yeast strain following the manufacturer's instructions (Clontech, Palo Alto, CA, USA).

\subsection{In Vitro Pull-Down Assay}

MBP:SDJ1, MBP:At5g09540 and MBP were immobilized on amylose resin and incubated with GST:WUS or GST, respectively, in the reaction buffer ( $\%$ glycerol, $1 \%$ triton- 100 , $50 \mathrm{mM}$ Tris- $\mathrm{HCl}\left(\mathrm{pH}\right.$ 7.4), $150 \mathrm{mM} \mathrm{NaCl}, 10 \mathrm{mM} \mathrm{NaF}, 1 \mathrm{mM} \mathrm{Na}_{3} \mathrm{VO}_{4}, 10 \mathrm{mM}$ leupeptin, $1 \mathrm{mM}$ phenylmethylsulfonyl fluoride (PMSF)) for $2 \mathrm{~h}$ at $4{ }^{\circ} \mathrm{C}$ with rotation. The amylose resin was then washed three times and subjected to immunoblot analysis to detect the precipitated GST:WUS protein using an anti-GST antibody (Cell signaling Technology, Shanghai, China). All pull-down assays were repeated three times with the similar results.

\subsection{Bimolecular Fluorescence Complementation (BiFC) Assays}

Full-length Arabidopsis WUS and Brassica napus WUS were cloned into $p 2 Y N$ vector containing N-terminal half of YFP to generate the fusion proteins of WUS-YFPn and BnWUS-YFPn, respectively. SDJ1, SDJ3, At5g09540, At4g11930 and BnSDJ1 cDNAs were cloned into $p 2 Y C$ vector containing C-terminal half of YFP to produce the fusion proteins of SDJ1-YFPc, SDJ3-YFPc, At5g09540-YFPc, At4g11930-YFPc, and BnSDJ1-YFPc, respectively. These constructs together with $35 S_{\text {pro }}:$ Coilin:RFP were introduced into Nicotiana benthamiana leaves through Agrobacterium infiltration so that Coilin-RFP protein can be localized at nucleus. Each BiFC experiment was repeated with four independent biological replicates. YFP fluorescence and RFP fluorescence were recorded using a confocal laser scanning microscope (Zeiss LSM 780) with excitation/emission values of $513 \mathrm{~nm} / 495-545 \mathrm{~nm}$ and $561 \mathrm{~nm} / 578-636 \mathrm{~nm}$, respectively.

\subsection{Co-Immunoprecipitation}

$35 S_{\text {pro }}:: G F P$ and $35 S_{\text {pro: }}:$ GFP:WUS in combination with $35 S_{\text {pro }}:: H A: S D J 3,35 S_{\text {pro }}:: H A: S D J 1$, or $35 S_{\text {pro }}: H A: A t 5 g 09540$ were introduced into Nicotiana benthamiana leaves through Agrobacterium infiltration to examine the interactions of GFP:WUS with HA:SDJ3, HA:SDJ1 and HA:At5g09540, respectively. The leaves were harvested two days after infiltration and frozen in liquid nitrogen for the isolation of nuclei. The isolated nuclei were lysed with reaction buffer (50 mM Tris-HCl, $\mathrm{pH}$ 8.0, $10 \mathrm{mM}$ EDTA, 1\%Triton X-100, $0.1 \mathrm{mM}$ PMSF, $1 \times$ Protease inhibitors cocktail) by incubation on ice for $30 \mathrm{~min}$. Clear lysates were mixed with diluting buffer ( $50 \mathrm{mM}$ Tris- $\mathrm{HCl}, \mathrm{pH} 7.5,150 \mathrm{mM} \mathrm{NaCl}, 3 \mathrm{mM}$ DTT, $2 \mathrm{mM} \mathrm{NaF}$ and $1 \mathrm{mM} \mathrm{NaVO3}$ ) and immunoprecipitated with GFP-Trap ${ }^{\circledR}$ agarose beads (ChromoTek). The beads were washed three times with the diluting buffer. The proteins recovered from the 
beads were subjected to immunoblot analysis using anti-GFP antibody (Cell Signaling Technology) or anti-HA antibody (Cell Signaling Technology).

\subsection{Chromatin Immunoprecipitation (ChIP)}

The $2 \mathrm{~g}$ of 4-day-old WT and 35S pro::HA:At5g09540 seedlings were harvested and fixed with $30 \mathrm{~mL} \mathrm{1 \%}$ formaldehyde under vacuum following addition of $2 \mathrm{~mL} 2 \mathrm{M}$ glycine to stop the crosslinking. Nuclei were isolated from tissue powder with $30 \mathrm{~mL}$ isolation buffer (10 mM Tris- $\mathrm{HCl}$ ( $\mathrm{pH} 8.0), 0.4 \mathrm{M}$ sucrose, $10 \mathrm{mM} \mathrm{MgCl}, 5 \mathrm{mM}$ 2-mercaptoethano ( $\beta$-ME), $1 \%$ Triton-X100, $0.1 \mathrm{mM}$ PMSF, $1 \times$ Protease inhibitors cocktail) and lysed with $300 \mu \mathrm{L}$ lysis buffer (50 mM Tris- $\mathrm{HCl}$ (pH 8.0), $10 \mathrm{mM}$ EDTA, 1\% SDS, $0.1 \mathrm{mM}$ PMSF, $1 \times$ Protease inhibitors cocktail). Chromatin was sheared to an average size of $200 \mathrm{bp}-500 \mathrm{bp}$ by sonication for total $550 \mathrm{~s}$ on a Covaris M220 Focused-ultrasonicator. About $10 \%$ of sonicated chromatin was collected as Input. The residue of sonicated chromatin was diluted with 10 times volume of dilution buffer (16.7 mM Tris- $\mathrm{HCl}(\mathrm{pH}$ 8.0), $1.2 \mathrm{mM}$ EDTA, $167 \mathrm{mM} \mathrm{NaCl}, 1 \%$ Triton-X100, $0.1 \mathrm{mM}$ PMSF, $1 \times$ Protease inhibitors cocktail) and precleared by incubation with $30 \mu \mathrm{L}$ of Dynabeads ${ }^{\circledR}$ protein A (Invitrogen). Then precleared chromatin was incubated with $30 \mu \mathrm{L}$ of Dynabeads ${ }^{\circledR}$ protein A coupled to an anti-HA antibody or anti-GFP antidody overnight at $4{ }^{\circ} \mathrm{C}$ with gentle agitation. The precipitated DNA was used as template for real-time RT-PCR analysis. The relative quantity (RQ) for each immunoprecipitated promoter region was calculated as $\mathrm{ChIP} /$ Input ratio. The relative quantity using Anti-HA antibody $\left(\mathrm{RQ}_{\mathrm{HA}}\right)$ was normalized to the relative quantity using Anti-GFP antibody ( $\mathrm{RQ}_{\mathrm{GFP}}$ ) as the relative enrichment of a promoter region. Four different loci in WUS promoter region were analyzed. Actin 7 was also used as a negative control. The primers used for ChIP-qPCR are listed in Supplemental Table S1. All ChIP experiments were performed with four independent biological replicates.

\subsection{Electrophoretic Mobility Shift Assay (EMSA)}

EMSA reactions were performed in a total volume of $10 \mu \mathrm{L}$ of binding buffer $(10 \mathrm{mM}$ HEPES (PH 7.8), $20 \mathrm{mM} \mathrm{KCl}, 1 \mathrm{mM} \mathrm{MgCl} 2,21 \mathrm{mM} \mathrm{DTT}, 7.5 \%$ Glycerol, 0.5\% Triton$100,300 \mathrm{ng}$ carrier DNA, $0.02 \%$ BSA) containing WUS promoter probes, MBP:WUS and MBP: SDJ1/SDJ3/At5g09540 at $22^{\circ} \mathrm{C}$ for $30 \mathrm{~min}$. The WUS promoter probe (CTAGAATGAATAATAAAAAAAGTGAAAACCGTTTGATCATAA) containing a TAAT motif was labeled with Texas Red at $3^{\prime}$ end. The unlabeled probe was used for competition experiments. The probe with the TAAT motif replaced by CCCC were used as negative control. The EMSA reaction products were resolved on $8 \%$ polyacrylamide gel and visualized using a ChemiDoc XRS molecular imaging system (Bio-Rad, Hercules, CA, USA).

\subsection{Transactivation Assay in Tobacco}

A 47 base pair minimal $35 \mathrm{~S}$ promoter was amplified and cloned with SpeI and XbaI sites into $p$ GreenII-0800-LUC to generate $p$ GreenII-0800-mini 35S-LUC vector. The $2.0 \mathrm{~Kb}$ WUS promoter (-126 bp--2127 bp) was cloned with KpnI and BamHI sites into $p$ GreenII-0800-mini

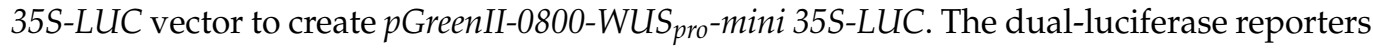
in combination with different effectors $\left(35 S_{\text {pro }}:: G F P, 35 S_{\text {pro }}:: G F P: W U S, 35 S_{\text {pro }}:: H A: S D J 3\right.$, $\left.35 S_{\text {pro }}:: H A: S D J 1,35 S_{\text {pro }}: H A: A t 5 g 09540\right)$ were introduced into Nicotiana benthamiana leaves through Agrobacterium infiltration. The activities of firefly luciferase (LUC) and Renilla luciferase (REN) were examined three days after infiltration using a Dual Luciferase Assay kit (Promega, Madison, WI, USA) on a luminometer (GloMax ${ }^{\circledR} 20 / 20$, Promega). The LUC activity was normalized to the REN activity (LUC/REN), and three replicate assays were performed with independent biological samples.

\subsection{Subcellular Localization of DnaJ Proteins}

$35 S_{\text {pro }}:: G F P: S D J 3,35 S_{\text {pro }}:: G F P: S D J 1$, and $35 S_{\text {pro }}:: G F P: A t 5 g 09540$ constructs in combination with $35 S_{\text {pro: }}:$ Coilin:RFP construct were introduced into Nicotiana benthamiana leaves through Agrobacterium infiltration. Then the colocalization of GFP:SDJ1, GFP:SDJ3 and 
GFP:At5g09540 proteins with Coilin:RFP protein in nucleus was examined using a confocal laser scanning microscope (Zeiss LSM 780) three days later after Agrobacterium infiltration.

\subsection{RNA Isolation and Real-Time RT-PCR}

Total RNA extraction, reverse transcription and qRT-PCR were performed as a previous report [28]. Three replicate assays were performed with independent RNA samples. All primers used for RT-PCR analysis are listed in Supplemental Table S1.

\subsection{Histochemical Localization of GUS Activity}

The histological analysis of $\beta$-glucuronidase activity was performed as the reported protocol [29]. GUS staining was performed with three independent transgenic lines with similar results.

\subsection{Accession Numbers}

Sequence data from this article can be found in the Arabidopsis Genome Initiative under the following accession numbers: WUS (At2g17950), SDJ3 (At1g62970), SDJ1 (At5g64360), At5g09540, At4g11930.

Supplementary Materials: The following are available online at https:/ /www.mdpi.com/2223-7 747/10/1/136/s1, Figure S1: At4g11930 interacts with WUS protein in tobacco epidermal cells in BiFC assay.,Figure S2: BnSDJ1 interacts with BnWUS protein in tobacco epidermal cells in BiFC assay, Table S1: The primers used in the experiment.

Author Contributions: T.J., F.L., S.L. and J.D. conducted experiments. T.J. analyzed data and prepared figures. T.H. designed research and wrote the manuscript. All authors have read and agreed to the published version of the manuscript.

Funding: This work was supported by grants from the Ministry of Science and Technique of China (2013CB967302).

Institutional Review Board Statement: Not applicable.

Informed Consent Statement: Informed consent was obtained from all subjects involved in the study.

Data Availability Statement: Data is contained within the article or supplementary material.

Conflicts of Interest: The authors declare no competing interests.

\section{References}

1. Laux, T.; Mayer, K.F.X.; Berger, J.; Jurgens, G. The WUSCHEL gene is required for shoot and floral meristem integrity in Arabidopsis. Development 1996, 122, 87-96.

2. Mayer, K.F.X.; Schoof, H.; Haecker, A.; Lenhard, M.; Jurgens, G.; Laux, T. Role of WUSCHEL in regulating stem cell fate in the Arabidopsis shoot meristem. Cell 1998, 95, 805-815. [CrossRef]

3. Schoof, H.; Lenhard, M.; Haecker, A.; Mayer, K.F.X.; Jurgens, G.; Laux, T. The stem cell population of Arabidopsis shoot meristems is maintained by a regulatory loop between the CLAVATA and WUSCHEL genes. Cell 2000, 100, 635-644. [CrossRef]

4. Georgopoulos, C.; Welch, W.J. Role of the Major Heat-Shock Proteins as Molecular Chaperones. Annu. Rev. Cell Biol. 1993, 9, 601-634. [CrossRef] [PubMed]

5. Lindquist, S.; Craig, E.A. The heat-shock proteins. Annu. Rev. Genet. 1988, 22, 631-677. [CrossRef] [PubMed]

6. Qiu, X.B.; Shao, Y.M.; Miao, S.; Wang, L. The diversity of the DnaJ/Hsp40 family, the crucial partners for Hsp70 chaperones. Cell. Mol. Life Sci. 2006, 63, 2560-2570. [CrossRef]

7. Miernyk, J.A. The J-domain proteins of Arabidopsis thaliana: An unexpectedly large and diverse family of chaperones. Cell Stress Chaperones 2001, 6, 209-218. [CrossRef]

8. Pulido, P.; Leister, D. Novel DNAJ-related proteins in Arabidopsis thaliana. New Phytol. 2018, 217, 480-490. [CrossRef] [PubMed]

9. Kampinga, H.H.; Craig, E.A. The HSP70 chaperone machinery: J proteins as drivers of functional specificity. Nat. Rev. Mol. Cell Biol. 2010, 11, 579-592. [CrossRef] [PubMed]

10. Rajan, V.B.V.; D'Silva, P. Arabidopsis thaliana J-class heat shock proteins: Cellular stress sensors. Funct. Integr. Genom. 2009, 9, 433-446. [CrossRef] [PubMed]

11. Finka, A.; Mattoo, R.U.H.; Goloubinoff, P. Meta-analysis of heat- and chemically upregulated chaperone genes in plant and human cells. Cell Stress Chaperones 2011, 16, 15-31. [CrossRef] [PubMed] 
12. Du, Y.M.; Zhao, J.P.; Chen, T.Y.; Liu, Q.; Zhang, H.L.; Wang, Y.; Hong, Y.G.; Xiao, F.M.; Zhang, L.; Shen, Q.H.; et al. Type I J-Domain NbMIP1 Proteins Are Required for Both Tobacco Mosaic Virus Infection and Plant Innate Immunity. PLoS Pathog. 2013, 9. [CrossRef]

13. Wang, W.X.; Vinocur, B.; Shoseyov, O.; Altman, A. Role of plant heat-shock proteins and molecular chaperones in the abiotic stress response. Trends Plant Sci. 2004, 9, 244-252. [CrossRef] [PubMed]

14. Bekh-Ochir, D.; Shimada, S.; Yamagami, A.; Kanda, S.; Ogawa, K.; Nakazawa, M.; Matsui, M.; Sakuta, M.; Osada, H.; Asami, T.; et al. A novel mitochondrial DnaJ/Hsp40 family protein BIL2 promotes plant growth and resistance against environmental stress in brassinosteroid signaling. Planta 2013, 237, 1509-1525. [CrossRef] [PubMed]

15. Boonsirichai, K.; Sedbrook, J.C.; Chen, R.J.; Gilroy, S.; Masson, P.H. ALTERED RESPONSE TO GRAVITY is a peripheral membrane protein that modulates gravity-induced cytoplasmic alkalinization and lateral auxin transport in plant statocytes. Plant Cell 2003, 15, 2612-2625. [CrossRef]

16. Christensen, C.A.; Gorsich, S.W.; Brown, R.H.; Jones, L.G.; Brown, J.; Shaw, J.M.; Drews, G.N. Mitochondrial GFA2 is required for synergid cell death in Arabidopsis. Plant Cell 2002, 14, 2215-2232. [CrossRef]

17. Harrison, B.R.; Masson, P.H. ARL2, ARG1 and PIN3 define a gravity signal transduction pathway in root statocytes. Plant J. 2008, 53, 380-392. [CrossRef]

18. Park, H.Y.; Lee, S.Y.; Seok, H.Y.; Kim, S.H.; Sung, Z.R.; Moon, Y.H. EMF1 Interacts with EIP1, EIP6 or EIP9 Involved in the Regulation of Flowering Time in Arabidopsis. Plant Cell Physiol. 2011, 52, 1376-1388. [CrossRef]

19. Park, M.Y.; Kim, S.Y. The Arabidopsis J Protein AtJ1 is Essential for Seedling Growth, Flowering Time Control and ABA Response. Plant Cell Physiol. 2014, 55, 2152-2163. [CrossRef]

20. Harris, C.J.; Scheibe, M.; Wongpalee, S.P.; Liu, W.L.; Cornett, E.M.; Vaughan, R.M.; Li, X.Q.; Chen, W.; Xue, Y.; Zhong, Z.H.; et al. A DNA methylation reader complex that enhances gene transcription. Science 2018, 362, 1182-1186. [CrossRef]

21. Zhao, Q.Q.; Lin, R.N.; Li, L.; Chen, S.; He, X.J. A methylated-DNA-binding complex required for plant development mediates transcriptional activation of promoter methylated genes. J. Integr. Plant Biol. 2019, 61, 120-139. [CrossRef] [PubMed]

22. Perales, M.; Rodriguez, K.; Snipes, S.; Yadav, R.K.; Diaz-Mendoza, M.; Reddy, G.V. Threshold-dependent transcriptional discrimination underlies stem cell homeostasis. Proc. Natl. Acad. Sci. USA 2016, 113, E6298-E6306. [CrossRef] [PubMed]

23. Ohta, M.; Matsui, K.; Hiratsu, K.; Shinshi, H.; Ohme-Takagi, M. Repression domains of class II ERF transcriptional repressors share an essential motif for active repression. Plant Cell 2001, 13, 1959-1968. [CrossRef] [PubMed]

24. Hiratsu, K.; Matsui, K.; Koyama, T.; Ohme-Takagi, M. Dominant repression of target genes by chimeric repressors that include the EAR motif, a repression domain, in Arabidopsis. Plant J. 2003, 34, 733-739. [CrossRef] [PubMed]

25. Matsui, K.; Tanaka, H.; Ohme-Takagi, M. Suppression of the biosynthesis of proanthocyanidin in Arabidopsis by a chimeric PAP1 repressor. Plant Biotechnol. J. 2004, 2, 487-493. [CrossRef]

26. Matsui, K.; Ohme-Takagi, M. Detection of protein-protein interactions in plants using the transrepressive activity of the EAR motif repression domain. Plant J. 2010, 61, 570-578. [CrossRef]

27. Clough, S.J.; Bent, A.F. Floral dip: A simplified method for Agrobacterium-mediated transformation of Arabidopsis thaliana. Plant J. 1998, 16, 735-743. [CrossRef]

28. Cui, Y.C.; Rao, S.F.; Chang, B.B.; Wang, X.S.; Zhang, K.D.; Hou, X.L.; Zhu, X.Y.; Wu, H.J.; Tian, Z.X.; Zhao, Z.; et al. AtLa1 protein initiates IRES-dependent translation of WUSCHEL mRNA and regulates the stem cell homeostasis of Arabidopsis in response to environmental hazards. Plant Cell Environ. 2015, 38, 2098-2114. [CrossRef]

29. Jefferson, R.A.; Kavanagh, T.A.; Bevan, M.W. Gus Fusions-Beta-Glucuronidase as a Sensitive and Versatile Gene Fusion Marker in Higher-Plants. EMBO J. 1987, 6, 3901-3907. [CrossRef] 